\title{
Teaching Research and Practice on Interscholastic Credit -- A Case Study on Assembly Language Programming
} \author{
Jing $X U^{a}$, Teng MIAO ${ }^{b}$, Yang XIAO' ${ }^{c}$, $\mathrm{JIN}^{\mathrm{d}}$, Na LI \\ ${ }^{1}$ College of Information and Electrical Engineering, Shenyang Agricultural University, \\ Shenyang, Liaoning, 110866, China \\ axujingsyau@163.com, ${ }^{\text {b}} 36569299 @ q q . c o m,{ }^{c} 1049372609$, \\ d26420093@qq.com, ${ }^{\mathrm{e}} 25614397 @ q q . c o m$
}

Keywords: Interscholastic credit, Teaching reform, Shenyang Agricultural University, Liaoning Shihua University, Assembly language programming.

\begin{abstract}
Interscholastic credit breaks the traditional teaching mode, achieving learning across time, space and region. With promoting the teaching level as the goal, the study advocates the student-oriented teaching idea, and sets up the teaching implementation plan, based on the cooperative course "Assembly Language Programming" offered by Shenyang Agricultural University and Liaoning Shihua University. It summarized the teaching effects of teaching practice, and raised some problems, which will provide some useful references for undergraduate teaching reform in Colleges or universities.
\end{abstract}

\section{Introduction}

Interscholastic credit refers to a kind of teaching mode that the students can receive the credit approved by the university he or she is in, by sharing the same course offered by other universities on the Internet. it has broken the traditional teaching mode. With the help of the technology and platform of the Internet, it has realized the cross-time, cross-space and cross-region learning, which has greatly met the needs of the students' individualized learning, improved the students' self-learning ability, and promoted the resources sharing among the universities.

On the basis of the Resource-shared Course of High Quality “Assembly Language” offered by Liaoning Shihua University, the writer carried out the teaching practice of interscholastic credit in this course in the computer major of Shenyang Agricultural University in 2016 and 2017. After two years of practice, the corresponding concrete implementation scheme has been formulated, the advantages of the interscholastic credit have been confirmed, and the experience has been accumulated. Meanwhile, some suggestions have been put forward to better carry out the practice.

\section{Implementation Scheme}

According to the regulations and requirements of the interscholastic credits and the teaching plan of the course "Assembly Language", the study takes as the subject the students of computer majors of 2014 in Shenyang Agricultural University. The course is offered by Liaoning Shihua University, and is shared by the students in Shenyang Agricultural University. The specific implementation scheme is carried out in three stages.

\section{Preparation Stage}

The teachers who either offer or use the course established an interscholastic course group before the course teaching, and communicated with each other on the teaching resources, the use of the platform, the composition and division of the members of the course group. It is also their duty to reach consensus and make necessary preparations for the implementation of the interscholastic credit.

\section{Implementation Stage}

The teaching process of interscholastic credit depends on two parts: online and offline. The online part mainly includes watching videos, online discussion and online homework, which is carried out 
by the teachers who either offer or use the course, with support of the third party technology. The offline part includes classroom teaching, the flipped classroom, and the practice on computer, which is in the charge of the teachers using it.

\section{Course Assessment and Mutual Recognition of Credits}

The score of the interscholastic credit course is made up of online and offline assessment. Online performance includes online watching, and online job completion. Offline performance includes the flipped classroom and the final exam results. The online performance reflects the students' self-study, while the flipped classroom reflects the spirit of teamwork and the students' ability to analyze and solve problems, and the final exam results have fully assessed the students' understanding and mastery of the content of the course. The score of the course is determined by the teachers using it, and is submitted to the teachers offering it. When the two parties confirm the score, the credit recognition is completed.

\section{Teaching Effect}

To Transform the Passive Learning into the Active Learning, and Improve the Students' Self-Learning Ability

The interscholastic credit breaks the traditional teaching mode, and makes the teaching mode true that combines the online and offline, in-class and off-class approach emphasizing the idea of "student-centered, and teacher-subordinated". Depending on online video, online learning, online test, online job, online discussion on network teaching platform, it carries out the flipped classroom by the mode of problem solving, discussion, discovery, case teaching. So the students' position and function of the subject is fully achieved.

Adopting the mode of combining the traditional classroom with the flipped classroom expands the student's thinking, broadens the student's vision, stimulate the students' interest in learning, turns the passive learning into the active learning, cultivates the students' ability to discover, to study and to solve problems, and guides students to use the network resources. So the self-learning ability is cultivated effectively.

\section{To Converse the Role of the Class and Encourage the Students to Stand on the Platform}

In order to make better use of the network resources and give full play to the advantages of "the flipped classroom”, the students selecting the course are divided into several learning groups, and the group is set as a learning unit, in which students are encouraged to stand onto the platform, trying the conversion of the role of the class, in the light of Chapter 5 and Chapter 6 of the "Assembly Language". Some students in the groups standing on the platform are serious, modest, rigorous and dedicated, showing a strong sense of comprehension, expressive ability and time concept in the process of preparing lessons. What's more, the teachers themselves also feel the inspiration, pressure and motivation from the students' performance.

To Introduce the Multi Evaluation Mechanism and Ensure That the Interscholastic Credit be Carried out Smoothly

In the teaching process, the interscholastic credit expands the evaluation of the students' off-class activities, and the proportion of the students' ordinary performance has been increased. Therefore it will better mobilize the students to actively complete such jobs as the online video, online test and online homework, which ensures that the off-class activities be carried out smoothly.

To Enrich Teaching Resources, Increase the Time of Off-Class Learning, and Enhance Students' Practical Skills

The interscholastic credit makes students more flexible in their learning time, place and progress. With the help of the network platform, it may be possible to take the courses of other universities. It can be repeated for more difficult and more important contents, and there is plenty of time for students to think and digest, improving the learning efficiency. In addition, due to the rich teaching 
resources provided by the Course of High Quality, the students' vision is broadened, and the trains of thinking are opened. Some classic cases provided by the online courses have also improved students' practical skills.

\section{To Promote the Research on Education and Teaching Reform and Improve Teachers' Teaching Level}

For the previous teaching of "Assembly Language”, the syllabus, teaching plan, the selection of the content of the course are completed by the members of the course group, consulting the successful experiences of other excellent universities, and approved by the college the teachers are in. but the specific implementation is completed independently by the members of the course group.

In the process of putting the interscholastic credit into the teaching practice, the teachers shared more teaching resources, absorbed the experience of the excellent teachers that offer the course by joint discussion and preparation. As a result, the trains of thinking of the course group teachers have been widened, with their teaching level promoted a lot. At the same time, we can actively communicate with the teachers offering the course, and rationally adjust the resources in the platform, in order to better meet the needs of the student learning.

\section{Problems in the Process of Implementation}

Having been carried out in the fall of 2016, the teaching practice of the interscholastic credit for “Assembly Language" has played a positive role both in the promotion of students' mastery of the course, the cultivation of students' learning ability, and in the improvement of teachers' teaching level. But there are still some problems in the process of implementation summarized as below.

\section{It is Hard to Maintain the Enthusiasm of the Students' Self Learning and the Execution is Deficient}

It is particularly important for students' self-learning ability and active participation when the flipped classroom is integrated to the traditional one, but the students vary in their self-consciousness and autonomy. So some students fail to watch the video before the class according to the teaching requirements, and some of them can not submit their homework on time. What's more, there are, to a certain degree, plagiarisms among them. In addition, some students fail to communicate with the teachers in time on the problems they met in the process of learning, which in return leads to the failure to achieve the learning goals, a sense of frustration, and further reduces the learning enthusiasm.

\section{There is Still a Lot of Room for the Promotion of the Teaching Effect of the Flipped Classroom}

Such factors have a direct impact on the teaching effect of the flipped classroom as no full adaption to the new mode of online learning, not good at raising questions and no strong initiative. In the flipped classroom, it is difficult for the teachers and students to complete the change of their own roles in a short time who are accustomed to the traditional teaching mode, because it is required that the comprehensive assessment of learning effect be made by the teachers' question, the students' discussion, the homework and test in the flipped classroom.

With the reform of education and teaching, it is believed that teachers and students will gradually adapt to this new teaching mode, and the advantages of flipped classroom will also be brought into full play.

\section{The Stability of the Online Learning Platform System Needs to be Improved}

Technical support serves as the prerequisite and basis for completing the interscholastic credit. But there is a frequent break during the process of watching videos, and the phenomenon occasionally occurs that the homework cannot be successfully submitted. In principle, students should not pay for the traffic generated by watching videos in universities, but some students say the traffic is actually generated. 


\section{References}

[1]Jiang Hongxia, Li Zhulin. Practice of the Course “Advertisement Design” for Undergraduates of Interscholastic Credit[J]. Journal of Shenyang Agricultural University(Social Sciences Edition) ,2016, 18(5): 598-601. (In Chinese).

[2] Chen Dongyu, Xujing. Exploration and Practice of the Teaching Mode of Interscholastic Credit Based on "Internet plus Education”[J]. Higher agricultural education. 2017, 4(4): 83-85. (In Chinese).

[3]Wu Shuang. Mutual Recognition of Interscholastic Credit Based on Resource Sharing in Universities[J]. Theoretic Observation, 2015,(2):135 -136. (In Chinese).

[4]Hu Xiaoyong, Zhang Ruifang, Feng Zhihui. Research on Problem-oriented Strategy in Flipped Classroom[J]. China Educational Technology, 2016,(7):93-98. (In Chinese).

[5]Luo Fei. Study on the Project of Interscholastic Credit[J]. Journal of Chifeng University(Natural Science Edition), 2014,(20):196-199. (In Chinese). 